\title{
IMPLEMENTASI METODE CENTRAL STEAM PADA PENINGKATAN PRODUKTIVITAS PENGUSAHA KECIL DI BERBAH, SLEMAN, YOGYAKARTA
}

\author{
Gunawan Madyono Putro, Prijoto \\ 1,2Universitas Pembangunan Nasional Veteran Yogyakarta \\ ${ }^{1}$ E-mail address Gunawan.madyono@upnyk.ac.id; 2 E-mail address prijoto@upnyk.ac.id
}

\begin{abstract}
Small entrepreneurs producing presto fish processed food in the village of Jogotirto Berbah experience problems in the fish processing process. The pressure tool used has not been optimal considering the length of time it takes to soften the fish and the inefficient fuel. This service program is designed to provide transfer of fish softening technology using the central steam method. Community service was carried out in the village of Jogotirto Berbah Sleman, involving 12 small entrepreneurs. The service provider provides training on using pressure tools with the central steam method for 2 sessions. Pengabdi provides pressure tools for the central steam method to small entrepreneurs and provides assistance for 5 months. The results of applying this method increased productivity by $50 \%$ and increased fuel efficiency by $40 \%$ so that the income of small entrepreneurs increased by 50\% every month.
\end{abstract}

Keywords: small entrepreneurs, presto fish processing, central steam method

\begin{abstract}
Abstrak
Para pengusaha kecil produsen makanan olahan ikan presto di desa Jogotirto Berbah mengalami kendala dalam proses pengolahan ikan. Alat presto yang digunakan belum dapat optimal mengingat lamanya waktu yang dibutuhkan dalam proses melunakkan ikan dan bahan bakar yang tidak efisien. Program pengabdian ini dirancang untuk memberikan alih teknologi pelunakan ikan mnggunakan metode central steam. Pengabdian masyarakat dilakukan di desaJogotirto Berbah Sleman dengan melibatkan 12 pengusaha kecil. Pengabdi memberikan pelatihan penggunaan alat presto dengan metode central steam sebanyak 2 sesi. Pengabdi memberikan fasilitas alat presto metode central steam kepada pengusaha kecil dan memberikan pendampingan selama 5 bulan. Hasil penerapan metode ini meningkatkan produktifitas sebanyak 50\% dan meningkatkan efisiensi penggunaan bahan bakar sebanyak 40\% sehingga pendapatan pengusaha kecil meningkat 50\% setiap bulan.
\end{abstract}

Kata Kunci: pengusaha kecil, pengolahan ikan presto, metode central steam 


\section{PENDAHULUAN}

Desa Berbah terkenal dengan usaha perikanan dengan memanfaatkan aliran air dari sungai Opak. Salah satu kelompok usaha yang berada di desa tersebut adalah Kelompok Usaha Kecil "Kalile". Kalile beranggotakan 12 orang pengusaha kecil yang memproduksi makanan ikan untuk dijual ke pasar tradisional atau dijual langsung ke konsumen. Jumlah produksi rata-rata setiap anggota adalah $8 \mathrm{~kg}$ ikan yang diolah menjadi makanan siap konsumsi. Bahan baku ikan segar mereka beli dari kelompok ikan “Mina Makmur”. Selama ini penghasilan setiap pengusaha kecil sekitar Rp.70.000,- sampai dengan Rp. 100.000,- ribu setiap hari.

Pasar ikan duri lunak masih sangat terbuka, namun kelompok ini mengalami kendala dalam proses pengolahan ikan, khususnya memproses menjadi ikan duri lunak. Alat presto yang digunakan dibeli dari toko perangkat rumah tangga dari pabrikan. Selama ini permaalahan yang dihadapi adalah: 1) Waktu proses cukup lama sekitar 2,5 - 3 jam untuk sekali masak; 2) bahan bakar yang digunakan sangat boros; dan 3) kualitas ikan olahan sebagian hancur. Permasalahan ini menjadi kendala bagi pengusaha kecil sehingga produktivitas kurang optimal.
Permaslahan utama yang dihadapi pengusaha kecil pengolahan ikan presto adalah teknologi produksi. Teknologi tepat guna dibutuhkan bagi pengusaha kecil untuk dapat meningkatkan produktivitas dan menekan biaya produksi menjadi lebih efisien. Alat presto dengan metode central steam menjadi solusi yang terapkan tim pengabdi kepada pengusaha kecil. Alat presto dengan sistem pemasakan kontinu ini dibuat dengan menggunakan satu tungku penguapan terpusat yang nantinya uap dapat dialirkan ke pancipanci presto secara bergantian dengan penambahan tekanan menggunakan kompresor sehingga selama pengambilan produk aliran uap bisa dialihkan ke soblok lainnya tanpa harus melepaskan uap. Dengan tungku penguapan yang terpisah ini aliran dan tekanan uap bisa diatur ke panci mana uap harus dialirkan tanpa harus mematikan kompor yang ada di tungku penguapan sehingga bahan bakar akan terpakai secara maksimal. Untuk menyelesaikan borosnya pemakaian soblok, akan terselesaikan dengan pemakaian tungku uap yang terpisah dengan panci prestonya sehingga apabila jebol kena panas hanya tangki uapnya saja dan cukup diganti dengan biaya yang relative lebih murah. Gambar 1 menjelaskan 
desain alat presto menggunakan metode central steam.

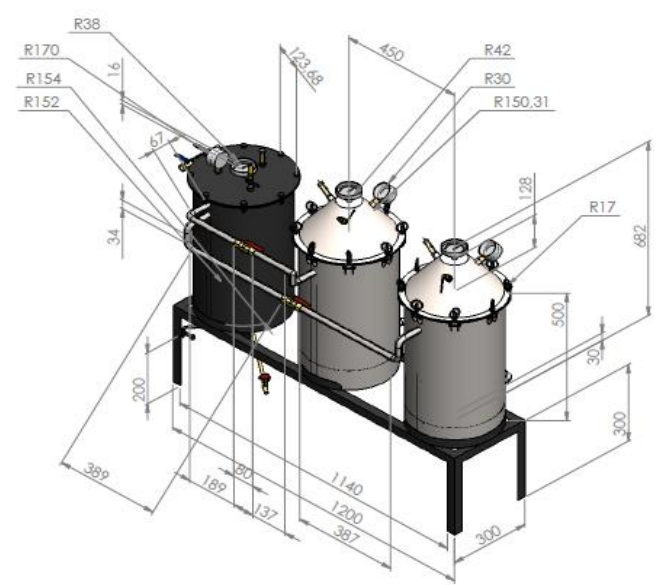

Gambar 1. Desain alat presto dengan metode central steam

Metode pelaksanaan kegiatan pengabdian masyarakat ini meliputi:

1. Penyuluhan

Penyuluhan dilakukan untuk memberikan wawasan pentingnya peningkatan usaha. Kegiatan ini penting dilakukan agar pengusaha kecil memiliki wawasan yang lebih luas pada tata kelola usaha. Kegiatan ini juga memotivasi anggota kelompok usaha kecil agar bersedia terlibat secara aktif dalam program pengabdian. Penyuluhan dilaksanakan satu kali pertemuan bertempat di rumah salah satu anggota.

2. Pelatihan

Pelatihan ditujukan untuk meningkatkan ketrampilan kepada anggota kelompok usaha kecil, khususnya dalam proses produksi ikan presto. Pengabdi mengajar cara menggunakan alat presto dengan metode central steam sehingga para anggota dapat mengaplikasikan secara tepat. Pelatihan ini dilaksanakan selama dua sesi. Sesi pertama adalah menjelaskan proses presto dan sesi kedua adalah praktek langsung.

3. Pemberian fasilitas

Fasilitas presto dengan metode central steam berupa alat presto diberikan oleh tim pengabdi kepada kelompok usaha sebagaimana disajikan pada Gambar 2.

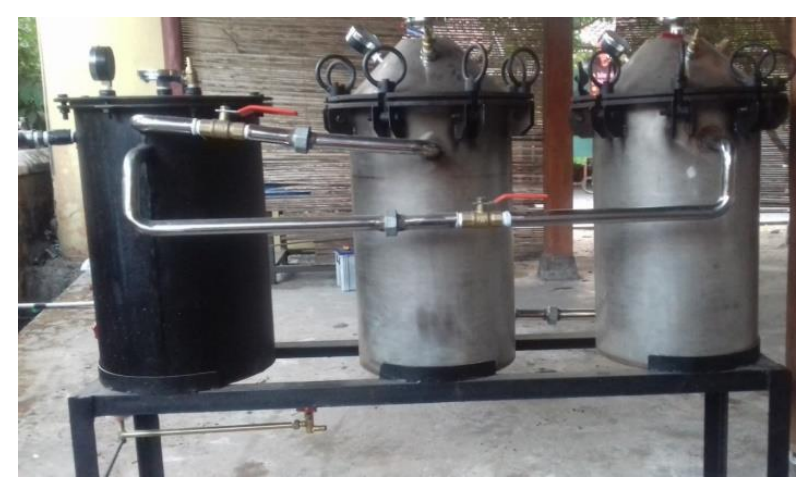

Gambar 2. Alat presto dengan metode central steam

4. Pendampingan

Alat presto dengan metode central steam diaplikasikan oleh kelompok usaha dengan pendampingan tim pengabdi. Tujuan pendampingan ini adalah untuk memberikan arahan selama implementasi alat dan memberikan jalan keluar jika terjadi permasalahan terkait alat ini. 
Pendampingan dilaksanakan selama 5 bulan sampai mitra benarbenar dapat mengoperasikan alat dengan baik.

\section{HASIL DAN PEMBAHASAN}

Pengabdian ini efektif dilaksakan selama 8 bulan. Hasil yang telah dicapai memberikan manfaat bagi mitra, pengabdi, dan perguruan tinggi. Berikut manfaat yang telah dirasakan oleh mitra. Hasil penerapan metode ini meningkatkan produktifitas sebanyak 50\% dan meningkatkan efisiensi penggunaan bahan bakar sebanyak 40\% sehingga pendapatan pengusaha kecil meningkat 50\% setiap bulan.

1. Peningkatan produktivitas

Mitra mendapatkan manfaat dari implementasi teknologi berupa peningkatan produktivitas ikan presto. Sebelum program ini dilaksanakan, produktivitas ratarata anggota adalah $8 \mathrm{~kg}$ per hari, namun setelah implementasi teknologi meningkat menjadi $12 \mathrm{~kg}$ per hari atau meningkat rata-rata sebesar 50\%. Hal ini terjadi karena dalam waktu bersamaan, dengan satu alat dapat memasak 2 soblok secara bersamaan.

2. Peningkatan efisiensi biaya Efisiensi biaya bahan bakar ratarata $40 \%$ setiap kali proses. Hal ini terjadi karena dengan satu alat tungku api dapat digunakan untuk memasak 2 soblok sekaligus sehingga bahan baku lebih efisien. Selain itu, penggunaan alat presto yang lama boros pada alat presto karena sering rusak di bagian bawah alat yang langsung terkena api. Namun dengan alat yang baru dapat menurunkan biaya perbaikan alat masak.

3. Peningkatan kualitas produk Pada saat menggunakan alat presto yang dibeli di pasaran banyak ikan yang rusak, namaun dengan teknologi central steam maka jumlah ikan yang rusak berkurang bahkan hampir tidak ada yang rusak.

4. Peningkatan pendapatan

Berdasarkan wawancara dengan para anggota diketahui bahwa penjualan mereka meningkat karena produktivitas mereka meningkat. Dengan demikian maka pendapatan juga meningkat. Ratarata peningkatan pendapatan mitra adalah sekitar 50\%.

Hasil pengabdian ini juga bermanfaat bagi pengabdi, antara lain:

1. Ide penelitian

Pengabdi telah menerapkan hasil penelitian sebelumnya dan melalui 
kegiatan pengabdian ini maka pengabdi menemukan ide-ide baru untuk mengembangkan teknologi sehingga dapat diusulkan pada proposal penelitian selanjutnya.

2. Publikasi

Tim pengabdi mempublikasisikan hasil pengabdian masyarakat pada seminar nasional sehingga menambah hasil publikasi. Selain itu, tim pengabdi juga menyusun buku ber ISBN dan mendapatkan Haki sehingga bermanfaat bagi peningkatan profesionalisme pengabdi.

Hasil pengabdian ini bermanfaat bagi UPN "Veteran" Yogyakarta, antara lain:

1. Pelaksanaan Tri Dharma Perguruan Tinggi

UPN "Veteran" Yogyakarta memiliki kewajiban tri dharma perguruan tinggi sehingga melalui kegiatan ini maka dharma ketiga telah dilaksanakan dengan baik.

2. Hilirisasi Penelitian

Hilirisasi penelitian pada kegiatan pengabdian masyarakat menjadi salah satu agenda UPN "Veteran" Yogyakarta. Kegiatan ini memberikan manfaat bagi perguruan tinggi karena hasil-hasil penelitian civitas akademika dapat diterapkan dan bermanfaat bagi masyarakat.

3. Reputasi Perguruan Tinggi

Kegiatan pengabdian masyarakat meningkatkan reputasi UPN "Veteran" Yogyakarta dari sudut pandang masyarakat sehingga keberadaan perguruan tinggi benar-benar bermanfaat bagi masyarakat

\section{PENUTUP}

\section{Simpulan}

Kegiatan pengabdian masyarakat telah dilaksanakan selama 8 bulan dan hasil yang dirasakan masyarakat adalah peningkatan produktivitas, peningkatan efisiensi produksi, peningkatan kualitas produk atau pengurangan produk yang gagal, dan peningkatan pendapatan mitra. Pengabdian juga memberikan manfaat bagi tim pengabdi maupun perguruan tinggi.

\section{Saran}

Teknologi presto dengan metode central steam dapat diaplikasikan di tempat lain yang relevan sehingga memberikan manfaat yang lebih luas bagi masyarakat. Penyempurnaan alat harus terus dilakukan untuk mengurangi risiko penggunaan alat sehingga aman bagi pengguna.

\section{Ucapan Terima Kasih}


Ucapan terima kasih disampaikan kepada UPN "Veteran" Yogyakarta melalui Lembaga Penelitian dan Pengabdian Kepada Masyarakat yang telah mendanai kegiatan pengabdian ini sehingga dapat dilaksanakan dan bermanfaat bagi semua pihak.

\section{DAFTAR PUSTAKA}

Jamhari, N., dan Jadmiko, WS. 2012. Cara Cepat Proses Presto. Yogyakarta . Andi Ofset.

Subekti, R. 2011. Pengaruh waktu dan temperatur terhadap olahan Presto, Yogyakarta , Andi Ofset Yunanto dan Bukhori, N. 2013. Aneka Olahan Ikan Presto Murah dan bergizi . Yogyakarta: Kanisius Buckle, K. A., R.A. Edwards, G.H. Fleet, and Wooton. 1985. Ilmu Pangan. Terjemahan. H. Purnomo dan Adiono. Universitas IndonesiaPress, Jakarta.

De Man, J.M. 1989. Kimia Makanan. Desrosier, N. W. 1988. Teknologi Pengawetan Pangan. Terjemahan Lawrie, R.A. 2003. Ilmu Daging. Jakarta:Universitas Indonesia Press. Subang: BPTTG Puslitbang FisikaTerapan - LIPI, 1990 Hal.1013. Warintek, Teknologi TepatGuna Pengolahan Pangan. https://selerasa.com /tipsmenggunakan-panci-presto-yangbaik-dan-benar Selerasa.com

https://cookpad.com/id/ resep/262420-bandeng-prestoduri-lunak homemade 